\begin{tabular}{ll}
\hline \hline MINING AND METALLURGY INSTITUTE BOR & ISSN: 2334-8836 (Štampano izdanje) \\
UDK: 622 & ISSN: 2406-1395 (Online) \\
\hline \hline
\end{tabular}

UDK: $65.011 / .012 .3(045)=111$

doi:10.5937/mmeb1802119S

Ljiljana Savić, Vladimir Radovanovic $^{* *}$, Mirjana Mrvaljevic ${ }^{* * *}$

\title{
ECONOMY MANAGEMENT WITH A FOCUS TO THE PRODUCTIVITY
}

\begin{abstract}
Knowing the essence of productivity and its importance for the economy of the company, but also for the national economy is a prerequisite for successful management in these spheres, as well as the implementation of productivity principles as one of the basic principles of economy. Productivity is viewed as a component of economic growth with the help of production function. Many theoretical interpretations point to the differentiated concepts of factor productivity at the enterprise level. The analyzed complex models for measuring the productivity of enterprises indicates that the productivity has been placed in the focus of economic management. The paper highlights the theoretical methodological problems in the application of certain models and ways to overcome them. The main goals of institutionalization in this area are harmonization the methodology for measuring the productivity of enterprises and national economy and enabling affirmation and importance of the productivity. The productivity of the national economy is most often measured by the real GDP per capita, often being the subject of analysis and composition of the GDP as different types of expenditures.The main goal of this paper is to enable better management to the economy of industrial enterprises, especially the mining companies, through improvement the productivity measurement.
\end{abstract}

Keywords: productivity measurements, productivity indicators, productivity approaches, economic growth

\section{INTRODUCTION}

Bearing in mind the constant orientation of the society to meet the greatest number of social needs in concrete conditions, there is a demand at the first place for production to be as productive as possible. Increasing productivity has become a constant task as well as a logical follower of increase in the social standards and continued advancement of society.

Countries with the productivity is at a higher level are far more favorable in the international trade because the world trade, and, as a rule, domestic trade do not take into account a low productivity and high production costs. The comparative advantages of the economically most developed economies of the world are primarily on the achieved productivity (an example of the Japan economy)

Productivity is one of the basic principles of economics without whose implementation there is no successful management of the economy, i.e. economic and social development.

Productivity as an economic principle is defined differently depending on what is meant by the economic content that it includes, or what it expresses as a measure of

\footnotetext{
*Faculty of Technical Sciences, Kosovska Mitrovica, ljiljana.savic@pr.ac.rs

** Faculty of Technical Sciences, Cacak

${ }^{* * * *}$ High School of Vocational studies, Pec, Leposavic
} 
economy success. In this relation, two extremes occur: the broader and narrower theoretical concept of productivity comprehension.

On the one hand, there are the economic theoreticians stating that the productivity is a measure of overall economic efficiency, and thus it is an expression of overall state of the economy, expressed in the terms of output / input $=$ productivity, where the inputs are available resources (labor, capital, land, material, energy, and even information), used in the production and trade of various goods and services.

Products and services are taken as the outputs either naturally or financially at various aggregate levels (individual, company, sector, industry, economy as a whole).

On the other hand, there are the authors who treat the productivity as the productivity of labor, since they assume that the productivity only expresses the efficiency of current work. This means that the productivity is treated as a partial measure of efficiency, or state of economy, as partial rather than as a universal economic principle. The productivity thus understood is usually expressed in terms of the labor productivity = production / current work.

The analysis of the essence of these concepts, the concepts of productivity, points to differences in the goals that should be achieved, nature and breadth of treatment of productivity treatment as an economic principle, economic content and economic categories that include productivity as an economic phenomenon. At the end, there are big differences in terms of measuring the productivity and applying the principles in the economy management. [1]

\section{INSTITUTIONALIZATION AND PRODUCTIVITY MEASUREMENT}

In theory and practice, this problem is often seen from different aspects and goals, and hence there are different opinions about the concept of productivity. Just because historical and other facts have influenced the definition of the concept of productivity, there are different understanding about the essence of this notion. Socially, politically, economically and other factors have influenced the definition of productivity.

A closer definition of this term is given by the physicists of the $18^{\text {th }}$ century as "ability to produce". At the beginning of the 20th century, the term productivity was used by the economists in the sense of relationship between the products and factors. In this sense, defining the concept of productivity as a global relationship between the output and input has been accepted by the Western economists and Organization for European Economic cooperation (OEEC), which has been worked since 1961 as the Organization for Economic Co-operation and Development (OECD). This understanding is seen in the latest works of the International Labor Office (ILO) from Geneva. [2]

As the relevant institution of measurement and analysis the productivity in Europe, the OECD in its reports [3] defines the national level of productivity measurements with the social gross product and / or added value, as the relevant outputs and certain alternatives to the inputs, hours of work, work effort (quality of work) and number employees. Of course, the OECD experts make difference between the quantitative and price aspect of productivity measurement. Although the financial way of productivity tracking is favored, it is mandatory to suggest the use of fixed price methods. The valid conclusion of the OECD study relates to a qualitative and quantitative approach in analyzing the working hours or effective working hours. It is quite clear that the number of working hours is a formal indicator (quantitative nature), and the actual utilization of employees in the working time is a vital indicator of productivity (qualitative aspect of productivity). The quantitative aspect of working hours (working time) can vary 
widely from country to country, from company to company (in the same country) from the nature of business, from the time of year (seasonal variations), etc. On the other hand, the qualitative aspect of productivity measurement relates to the quality of daily work activities in a single workplace, which belongs to a domain of human resources management, that is, the monitoring and evaluation the employees by the executives in all organizational units of the company. [4]

At the level of USA economy, the labor productivity is monitored analytically at the level of each enterprise, industry, and American economy as a whole. These monitoring and analysis are of a financial nature and are done through a chain or base indices, with different outputs and inputs depending on: 1) Whether the analysis is performed at the enterprise level as a whole or some of its units and 2) which aspect of productivity is monitored and analyzed. Reports on quarterly or annual aggregate productivity trends in the USA have been published within the Bureau of Labor Sta tistics since 1947. [5] In addition, this leading world house of statistics productivity (not only labor) in principle analyzes the productivity from three aspects [5]:

Work productivity which has a working input in its basis; productivity is monitored at the level of the economy as a whole (all enterprises, i.e. the economy and nonbusiness are expressed in our terms), but it is particularly expressed in the agriculture, non-financial institutions, production corporations etc. The labor productivity indicator is monitored quarterly.

Multifactor productivity - inputs and labor are the inputs for the analysis and monitoring of this aspect of productivity; this indicator is monitored on an annual basis.

The KLEMS model of multifactor productivity - this is a complex model of productivity tracking, where besides work and capital the following inputs are specially specified: energy, materials and services; this indicator is particularly interesting only for the manufacturing companies, and is monitored on an annual basis.

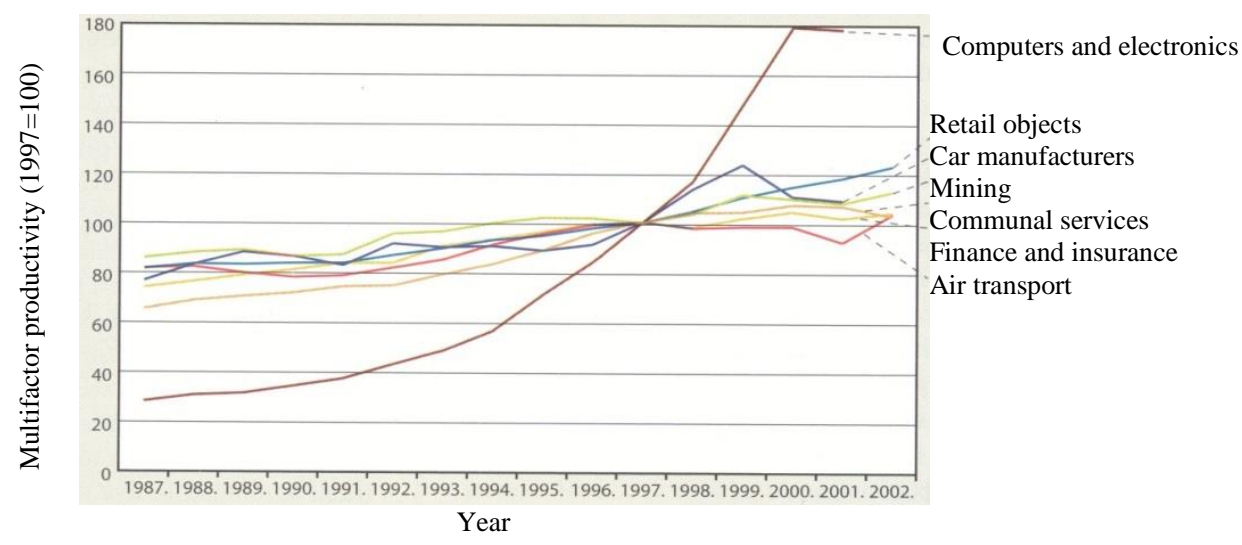

Fig. 1 Growth of multifactor productivity in different industries

Source: "Productivity and Costs", Bureau of Labor Statistics, available at http//data bls.gov/cgi-bin [6]

In the example shown in Figure 1, there are trends related to the multifactorial productivity in several branches of the US economy from 1997-2002, with an increase of $78 \%$ in the period from 1997 (which is equal to $100 \%$ ) to 2001 (when the level 
reached 178), and with almost six times increase since 1987 the growth of multifactorial productivity in the computer and electronics sector has far exceeded productivity growth in the retail, car manufacturing, mining, utilities, finance and insurance, air transport and most other branches.

Should Managers Use the Multifactorial or Partial Productivity Measures? Generally speaking, they should use both measures. Multifactor productivity shows the overall productivity level of the company compared to its competitors. In the end, that is the most important thing. However, the measures of multifactorial productivity do not show how much the individual contribution that work, capital, material or energy give to the total productivity. In order to analyze the contributions of these individual components, the managers must use the partial productivity measures. This will help them to determine which factors need to be corrected, or in which areas the correction can most likely reflect on the total productivity. [7]

\section{PRODUCTIVITY CENTERS - OUR EXPERIENCES}

The main objective of institutional measurements the productivity was to harmonize and standardize the methodology for measuring productivity so that the productivity of national economies would be comparable, that is, each country could determine whether its productivity is increasing or not in relation to the productivity of other countries.

In parallel with the start of institutional and systematic measurement of the productivity of national economies, productivity centers (firstly in the countries of Western Europe, then in Japan) are being formed in many countries of the world, whose goal is to promote and improve the productivity in enterprises. The main goals of productivity centers are to promote the importance of productivity, and to improve the methodology for measuring productivity of enterprises through the harmonization. [8]

In our country, it is understood, the experiences of other countries are used, but some own results have been achieved, especially in the work of the Federal Institute of Labor Productivity (which was established in October 1957), which are a serious contribution to the problem of measuring labor productivity. The institution is financed from the budget. At that time, very useful cooperation with the European Productivity Agency (EPA) in Paris was developed. After several changes in the name, the stagnation and problems in the economy were very strong in the work of the institute. In 2005 , after the privatization and transition to the ownership of a consortium of employees, the legal form was changed into a joint stock company and soon in the limited liability company. Today it is the Institute of Business Improvement Ltd. Belgrade.

\section{PRODUCTIVITY, PROFIT AND ECONOMIC GROWTH}

Productivity and profit are two sides of the same phenomenon, two angles of looking at the same process "the process of continuous and successful business". For businesses, a higher productivity - that is, to achieve more with less resource - means lower costs, lower prices, quick service, higher market share and higher profits.

According to Professor Drucker, the productivity represents the wealth of people, as it allows a part of the newly created value to flow into the increased quality of life of the broad social levels. This confirms and states that the "civilization and productivity go hand in hand". This is the reason why in all, and especially in highly developed countries, research is being carried out and ways to increase the labor productivity are found. 
Every growth of the economy can be achieved [9]: 1) through the additional input, 2) through the productivity growth.

By help of the production function, it is possible to describe simply the mechanism of economic growth. Economic growth is a production increase achieved by an economic community. It is usually expressed as the annual growth percentage depicting (real) growth of the national product. Economic growth is created by two factors, so that it is appropriate to talk about the components of growth. These components are an increase in the production input, and increase in the productivity.

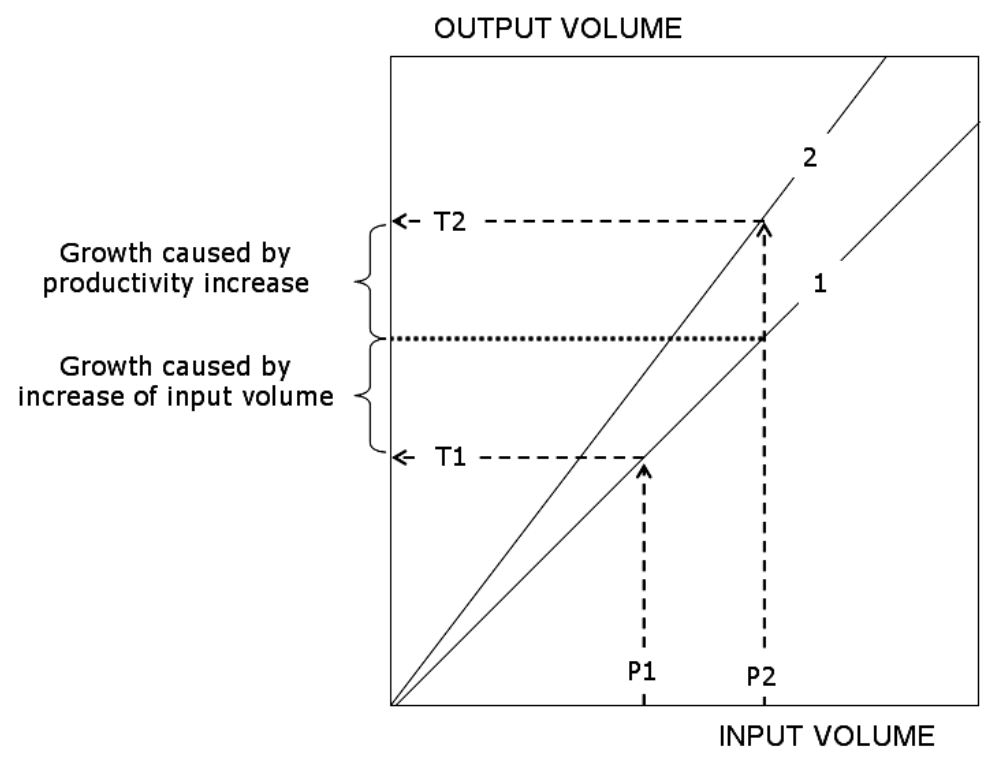

Fig. 2 Components of economic growth

Source: Seppo, S 2006, Productivity: Theory and Measurement in Business, University of Applied Sciences, Finland [10]

As shown in Figure 2, it becomes evident that the production increases from $\mathrm{T} 1$ to T2. Measured in absolute terms, the economic growth is T2-T1, while speaking proportionally it is $\mathrm{T} 2-\mathrm{T} 1 / \mathrm{T} 1$. At the same time, increasing the value from $\mathrm{P} 1$ to $\mathrm{P} 2$ is measured in the use of production input. Now, both years can be represented by a graph of the production function, each function is related to a particular year, e.g. 1 and 2. Two components differ in the output growth: growth caused by input and growth due to increase in the productivity. A profit based increase is determined by moving along the production function for a certain input increment, e.g. from P1 to P2. The growth characteristics affected by the increase in input are that the relationship between the output and imprint remains unchanged. An increase in output means the change of production function simultaneously with the change in the output / input ratio. In the other words, the growth of output corre- 
sponds to a shift in production function, generated by an increase in productivity.

Therefore, the increase in productivity is characterized by the shift of the production function to the output / input ratio. The total productivity formula that follows is:

Total productivity = output quantity/ input quantity

According to this formula, the changes in input and output must be measured including both quantitative and qualitative changes.

In practice, the quantitative and qualitative changes occur when the relative quantities and relative prices of different input and output factors change. In order to emphasize the qualitative changes in the output and input of the total productivity formula, the following will be given:

Total productivity = Output quality and quantity / Input quality and quantity

Model of the national economy - In order to measure the productivity of nation or industry, it is necessary to operationalize the same concept of productivity as in the business, yet, the object of modeling is substantially wider and the information more aggregate. Calculations of the total productivity of nation or industry are based on the time series of the SNA, System of National Accounts, formulated and developed for half a century. National accounting is a system based on the recommendations of the UN (SNA 93) to measure the total production and total income of a nation and how they are used. Measurement of productivity is at its most accurate in business because othe availability of all elementary data of the quantities and prices of the inputs and output in production. We want to analyze more comprehensive entity by measurements, more data need to be aggregated. In the productivity measurement, combining and aggregating the data always involves the reduced measurement accuracy.

\section{INDICATORS OF PRODUCTIVITY OF THE NATIONAL ECONOMY}

Productivity is considered as the basic statistical information for many international comparisons and country performance assessments, and there is a great interest in comparing them internationally.

The productivity of the national economy is measured by the amount of the gross domestic product (GNP) per capita.

The Internationally Recognized Standards: The National Accounts System 2008 (SNA 2008) and the European System of Accounts 2010 (ESA-2010) are the basic methodological framework in terms of defining and evaluating categories, applied classifications and method of calculation. The annual macroeconomic accounts and the most important macro-economic aggregates for the Republic of Serbia are published in accordance with these internationally recognized standards. The published data are available since 1995.

The most well-known and most used aggregate of the National Account System is the gross domestic product (GDP), which is an indicator of the total economic activities at the country level. Gross domestic product is the market value of all final goods and services produced in one country for a specific period of time. The GDP is calculated at the current and constant prices. The calculation of the GDP at constant prices aims to show the real dynamic and structural changes arising independently of the impact of prices.

If the GDP is viewed from the point of view of total expenditures, it can be explained by the components: consumer spending (C), investments (I), government expenditure $(\mathrm{G})$, and net exports (NX). 
In addition to the national currency calculation, for the purposes of international comparisons, the calculation of the GDP, and other macroeconomic aggregates in USD and EUR is made at the average annual rate.

There are three approaches to the calculation of the GDP, production, processing and revenue (contained in chapter 6 , national accounts, and methodological bases of the national accounts system) [11].

Gross domestic product, GDP, calculated according to the production method is the sum of gross value added (GVA) of all resident institutional units plus the amount of product tax and reduced by the amount of subsidies on products. Gross value added is obtained by the production method, as a difference between the total output (production value) and inter-phase consumption.

According to the expense approach, the aggregate forests: the final consumption (households, non-profit institutions that provide services to households and the state) invest in the basic funds changes in supply and export values minus the value of imports of goods and services. Spending of goods and services in the production process (inter-phase consumption) and investments do not have the character of final consumption.

The GDP can also be accounted by the income method as a sum of gross salaries of employees, business surplus / mixed income and taxes reduced for subsidies on products and on production.

The productivity of the national economy is measured by the gross domestic product per capita (GDP per capita) in current and fixed prices. When the nominal GDP is calculated, the current prices are used. When calculating the real GDP, the fixed base year prices are used and based on them the value of production of goods and services in that economy is attributed. Since real GDP does not affect price changes, changes in real GDP reflect only changes in the quantities produced. When it comes to the growth of the economy, this growth is expressed as a percentage change in the real GDP.

The Serbia's Gross Domestic Product (GDP) in 2016 amounted to RSD 4,261 billion at current prices and was $5.4 \%$ higher than in the previous year, while the real growth, calculated at fixed prices, was $2.8 \%$, the Statistical Office of the Republic of Serbia reports.

By activity, in 2016, at fixed prices in the agriculture, forestry and fisheries sector, the growth of gross value added was $8.1 \%$, the sector of processing industry $2.2 \%$, the wholesale and retail sector and motor vehicles repair 3\%, the sector information communication $5.8 \%$,and in the electricity, gas and steam sector, $6.3 \%$. The real fall in gross value added was recorded in the mining sector of $3.7 \%$.

In the use of GDP, the share of expenses for personal consumption of households was $71.4 \%$, expenses for final consumption of the state $16 \%$, gross investment in basic funds $17.7 \%$, exports of goods and services $50 \%$ and imports of goods and services $57.5 \%$.

\section{PRODUCTIVITY OF THE COMPANY}

Many works dedicated to the global productivity of factors and labor productivity have contributed to the improvement of enterprise productivity measurement. In this way, support was provided in more efficient management of the company's economy.

Global productivity (factor productivity) or total resources implies that productivity expresses the overall efficiency of the economic system as the state of economy expresses the relationship between the total output and input. On the contrary, the productivity of work only partially expresses 
the efficiency of economic system, since it includes only one aspect of input, current work.

Jean Fourastie, in his book (La Productiva, page 53-65 [12]) as a member of the Committee for the Study and Measuring Productivity of the National Committee for productivity of France, gives a "recapitulation of productivity concepts" and systematizes them into the following productivity indicators derived from the Theory of Productivity factors:

First, productivity in relation to work $=$ Production / Current work

Second, productivity in relation to any other factor $=$ Production / Quantity of this factor

Third, global productivity factors = Production / all factors

Fourth, integral labor productivity $=$ Production / Integrated work (current + tangible)

Fifth, net productivity $=$ net product $/$ (production-external factors) current work

With the abandonment of the value theory and change in theoretical thinking about productivity, the prevailing opinion was that capital, along with work and land, has an equally important role in creating products, and an effort to increase productivity. This was the basis for the emergence of the concept of production function and the measurement of total factor productivity. Measurement of the production function and total productivity of factors, through the relationship between products and all invested factors of production, began in the middle of the $20^{\text {th }}$ century.

\section{MEASURING PRODUCTIVITY OF THE COMPANY}

When we express or measure productivity of a company, we notice two groups of problems: 1) the problem of expressing output and 2) the problem of measuring the input. Classical production productivity can be measured by the ratio of the output quantity, volume of production, and quantity of work invested. If the output is defined in one type of product, then

$$
\mathrm{P}=\mathrm{Q} / \mathrm{L}
$$

where

- $Q$ is the quantity of usable values of products and services expressed by physical units of measure, and the Lamount of invested work is expressed in the number of employees or hours spent.

In order to be able to measure the outputs in processes with a heterogeneous production program, two measurement approaches can be used. The first is the application of coefficient of equivalence by which the quantity of different products is reduced to one conditional product. The conditional product is one of products from the assortment of company and presents the results of management decision. The equivalence coefficient is calculated as the ratio of the number of norms of hours needed to produce the conditional product and the norm of hours needed for production of the observed product

$\mathrm{Kei}=\mathrm{Nsi} / \mathrm{Nsu}$

- Nsi - the norm of hours of the i-th product,

- Nsu - the norm of hours of conditionnal product.

Then the total output is:

$\Sigma$ Kei $\odot$ Ni ॰ Q:

where

- Qi- number of product pieces of i-th product

Another approach to expressing an output quantity in the case of a heterogeneous product or service program is based on the use of value units or prices. When using this approach, there may be some doubts about whether internal ones are 
used, for example, cost price, or market price. Bearing in mind that the prices of some products are very variable, and that some prices are formed in the conditions of dominance in the market, some companies decide to show the amount of the output at internal prices (cost price). by:

Productivity in these cases is measured

$$
\mathrm{P}=\Sigma \mathrm{Q} \cdot \mathrm{Cq} / \mathrm{L}
$$

where

- Q - Produced quantity,

- Cq - market price per unit of product.

$$
\mathrm{P}=\Sigma \mathrm{Q} \cdot \mathrm{Tq} / \mathrm{L}
$$

where

- Tq- cost price per unit of product.

These methodological problems can be overcome using the fixed prices. By calculation the physical product in the regular chains of the selected base period, a change in the quantity of products and services is expressed, not a change in prices.

With regard to determining the size of the input except for the work, or any other individual input factor, the input costs can be summarized as the labor inputs, material costs, energy costs, amortization costs, interest costs and the multifactor productivity is [13].

$$
\begin{aligned}
& \quad \mathrm{P}=\Sigma \mathrm{Kei} \cdot \mathrm{Nsi} \cdot \mathrm{Qi} / \mathrm{Tr}+\mathrm{Tm}+\mathrm{Te}+ \\
& +\mathrm{Ta}+\mathrm{Tk}
\end{aligned}
$$

Where

- Tr - labor costs

- Tm - material costs

- Te - energy costs

- Ta - amortization costs

- Tk - interest costs

Inputs can be calculated by fixed price method where some elements are calculated differently.

\subsection{The Kurosawa Structural Approach}

Kacukio Kurosawa, a professor at the Tokyo University, supports that the productivity measurement system is to be built in accordance with the hierarchy of leadership. In his works, he places productivity at the focus of economy management.

A very precisely defined working time structure is used to define the labor productivity measurement ratios.

In implementing his structural concept for measuring productivity at the enterprise level, Kurosawa combines the added value with various physical parameters and other related variables. The added value of the company can take several forms. Management objectives dictate the choice of form of added value.

$$
\text { Real added value }=\Sigma \mathrm{Pi} \cdot \mathrm{Qi} / \mathrm{Ip}-\Sigma \mathrm{Si}
$$
$\cdot \mathrm{li} / \mathrm{Is}$

$\Sigma \mathrm{Pi} \cdot \mathrm{Qi}$ - gross output in the current period at current prices

$\Sigma \mathrm{Si} \cdot \mathrm{li}$ - industrial costs in the current period at current prices,

- Ip - product price index,

- Is - average input price index.

\subsection{The Lolor Approach}

Alan Lolor treats productivity as a comprehensive measure of the efficiency and effectiveness of the company and looks at it from the point of view of objectives, efficiency, effectiveness, comparability from the point of view of trends.

In Lolorov's approach, there are two levels in measuring productivity within the company: primary and secondary. The primary level shows the total earnings productivity expressed by the ratio of total earnings / cost of conversion. The conversion costs include the total personal income $(\mathrm{v})$, total purchased services (Ps) and depreciation $(\mathrm{K})$ $\mathrm{E}=$ total income $/$ conversion costs $=\mathrm{T} / \mathrm{C}$

At the second level, it expresses the profitability of profitability as a ratio of profit and total conversion costs.

$\mathrm{Ep}=$ profit $/$ conversation costs $=\mathrm{P} / \mathrm{C}$ or since $\mathrm{P}=\mathrm{T}-\mathrm{C}$

$$
\mathrm{Ep}=\mathrm{E}-1
$$


The total cost of conversion contains the costs when resources are productively used, and costs of unused resources. True production work, in contrast to the auxiliary work, directly adds value to the raw materials. Lolor uses two more secondary productivity measures: working capital and productivity of supplies.

Potential of the total enterprise income is earnings that would be obtained if the entire input was fully utilized without the cost of unused capacity. In the other words, $\mathrm{Cd}=\mathrm{CC}$. For that matter:

Potential earnings Tpot $=\mathrm{T} /$ Total $\mathrm{Cd} \times \mathrm{C}$

\subsection{The Approach of National Authors}

On this occasion, it is necessary to emphasize the special contribution of Prof. Dr D. Radunović in the study on productivity of the company. By giving contribution in the analysis of the productivity of mining companies (coal mines), Radunović has developed his own concept for applying productivity in this business. Although this is a homogeneity - uniformity of assortments in the mining production, and here the theoretical and methodological problems arise. Four methods are applied: natural, natural-conditional, working and monetary method, as well as a combination of natural-conditioned methods. In his approach, he chose the productivity of current work. He analyzed factors in the mining production.

Prof. Dr Stevan Kukoleca, although his approach is based on the concept of labor productivity, uses only the term productivity because he rejects the thesis about factor productivity. He treats the productivity as one of the three economic principles in addition to the economics and profitability, each focused on a particular economic content. The principle of productivity is viewed as the principle of economic work whose content is focused on the relevant relationship between the products and labor costs. In order for productivity to be a feature of a specific measure of the quality of the company's economy, only the quantity of product that is being realized or, more precisely, which has been realized should be taken into account. In this way, an increase in the consumption potential and living standards is ensured which contributes to the level of macroeconomics.

Measuring productivity also implies the qualitative and quantitative expression of changes under the influence of a certain factor, not only the product and the cost of labor, but also their mutual relationship.

\section{CONCLUSIONS}

Productivity is undoubtedly at the center of both theoretical research and concrete economic practices, whether it is a national economy or the economy of a company. This is shown by extensive literature devoted to the productivity, which is in the focus of interest not only of some scientists and researchers, teams of specialists but also national and international institutions dealing with productivity improvement. When adding all those working on productivity problems in specific companies all around the world economy, then a really good picture of this significant economic phenomenon is obtained.

Productivity is not interpreted in the literature uniquely and different models for its measurement appear. Based on the differrence in economic sustainability that it encompasses, or what it expresses as a measure of the success of the economy, two concepts exist in the contemporary literature. The first concept of labor productivity is a relationship between the product and invested work as an input. This is the oldest and most frequently used indicator of partial 
productivity. Quality management of the organization through the labor productivity model implies increasing the level of results while reducing the effective working hours needed to achieve these results. It is also necessary to discover causes that affect the efficiency and effectiveness of the company.

Another concept of the productivity of all factors is the relationship between products and all inputs. The fixed price method is the standard productivity measurement method. By the method of fixed prices, heterogeneous products and inputs are reduced to a monetary value, thus overcoming the problem of their incompatibility.

By determining the multifactor productivity, we do not get knowledge on contribution the certain factors to overall productivity. Multifactor productivity as a synthetic indicator is not an analytical instrument that enables an adequate diagnosis of the condition and cause for taking the appropriate management actions accordingly.

Measuring the levels and productivity changes (single-factor productivity), while monitoring changes in the scope and structure of individual factors, can provide conclusions about which measures reducing consumption or input lead to the highest growth in results.

At the national economy level, it is necessary to operationalize the same concept of productivity as in business, but the goal of modeling is much wider and the information is more aggregate. It is usual that the productivity of a national economy is expressed as a gross domestic product per capita. Institutionalization has contributed to data comparability, which is a step to increase productivity.

The increase in productivity can be due to the savings made in the use of other inputs, which cannot be shown by a partial expression of labor productivity. The net saving of all inputs and the resulting increase in total productivity can only be expressed when the product is compared with all inputs, which means measuring the overall productivity of factors. Productivity as a measure of success is important for the mining companies.

\section{REFERENCES}

[1] M. Nikolic, N. Malenovic, D. Pokrajcic, B. Paunovic, Economy of the Enterprises, Faculty for Economics, Belgrade (2005), pp. 264-266 (in Serbian)

[2] J. Prokopenko, Productivity Management International Labor Office Geneva (1987) p. 3

[3] Measuring Productivity: Measurement of Aggregate and Industry - Level Productivity Growth (2002), OECD publishing

[4] S. Acimovic, N. Fabris, Reliability and Possibilities of Improving Models Productivity at Different Organizational Levels, Original scientific paper, received: March 02, 2011, p. 40.

[5] Bureau of Labor Statistics, USA, number 20212, 21st May 2008

[6] Productivity and Costs, Bureau of Labor Statistics,http//databls.gov/cgibim/survey Chuck Williams, Management Principles, Data Status. Belgrade, 2010, p. 329

[7] D. Pokrajcic, Economics of the Enterprises, author's edition, Belgrade, 2002, p. 188

[8] Genesca, B.E., Grifell, T.E. 1992 "Profits and Total Factor Productivity: A Comparative Analysis" Omega. The international Journal of Management Science, Vol .20, No 5/6, p. 554

[9] Seppo, S 2006, Productivity: Theory and Measurement in Business, University of Applied Sciences, Finland, p. 2 
[10] Statistical Yearbook of the Republic of Serbia 2016

[11] D. Radunovic, Productivity of the Work in Theory and Practice, Belgrade, 1967, p. 24 (in Serbian)
[12] O. Jasko, M. Cudanov, M. Jevtic, J. Krivokapic, Fundamentals of the Management Organization, FON Belgrade, 2014, p. 331 (in Serbian) 